\title{
Functional Changes of the Upper Esophageal Sphincter in Gastroesophageal Reflux
}

\author{
Roberto Oliveira Dantas ${ }^{1}$ (1) \\ ${ }^{1}$ Department of Medicine, Faculdade de Medicina de Ribeirão Preto, \\ Universidade de São Paulo, Ribeirão Preto SP, Brazil \\ Address for correspondence Roberto Oliveira Dantas, associate \\ professor, Department of Medicine, Ribeirão Preto Medical School, \\ University of São Paulo, Av. Bandeirantes 3900 Campus da USP, \\ Int Arch Otorhinolaryngol 2022;26(4):e519-e523. \\ Ribeirão Preto, SP, 14049-900, Brazil (e-mail: rodantas@fmrp.usp).
}

\begin{abstract}
Keywords

- gastroesophageal reflux

- upper esophageal sphincter

- dysphagia

- heartburn

Introduction The upper esophageal sphincter (UES) is a muscular structure located at the transition from the pharynx to the esophagus, with the cricopharyngeal muscle as the most important component. During gastroesophageal reflux, the pressure in the UES elevates, which is apparently a protective mechanism to prevent esophagopharyngeal reflux and airway aspiration. In gastroesophageal reflux disease (GERD), there may be functional changes in the UES.

Objective The objective of the present review was to determine UES functional changes in GERD.

Data Synthesis In healthy individuals, gastroesophageal reflux causes an increase in the UES pressure. This response of the sphincter is at least partially impaired in patients with GERD. In the disease, the UES has a reduced length and decreased resting pressure. However, other publications found that in chronic gastroesophageal reflux the basal sphincter pressure increase, differences which may be consequent to the measurement method or to disease severity. The UES opening during swallowing has a smaller diameter, and the bolus transit time through the sphincter is longer.

Conclusion The UES of patients with GERD does not open as expected and the bolus flow through the sphincter is longer. This behavior may be associated with dysphagia, a frequent complaint in patients with GERD.
\end{abstract}

\section{Introduction}

The upper esophageal sphincter (UES) is a high-pressure region located between the pharynx and the esophagus, resulting from the contraction of the inferior pharyngeal constrictor, the cricopharyngeal muscle and the proximal cervical esophageal muscle. ${ }^{1}$ The major functional component of the UES is the cricopharyngeal muscle. This muscle helps maintaining a relatively high UES pressure, which can be either decreased or increased in consequence of different stimuli. The cricopharyngeal muscle is structurally, biochemically, and mechanically distinct from pharyngeal and esophageal muscles. ${ }^{1}$ It contains more elastic connective tissue and sarcolemma than most other striated muscles, and this high degree of elasticity contributes to the opening of the UES. ${ }^{2}$

The UES pressure is not constant. The UES pressure increases in response to slow esophageal distension, pressure on the pharyngeal mucosa, inhalation, awaking, phonation, posture, esophageal secondary peristalsis, stress, increase in intra-abdominal pressure and gastroesophageal reflux; and decreases with anesthesia, sleeping, swallowing, belching, quick esophageal distension, vomiting, exhalation, and in childhood and elderly age. ${ }^{1-8}$

The motor function and sensitivity of the UES are controlled by branches of the vagus and glossopharyngeal received

November 13, 2019

accepted

October 22, 2020

published online

July 28, 2021
DOI https://doi.org/ 10.1055/s-0040-1722160. ISSN 1809-9777.

\footnotetext{
(c) 2021. Fundação Otorrinolaringologia. All rights reserved.

This is an open access article published by Thieme under the terms of the Creative Commons Attribution-NonDerivative-NonCommercial-License, permitting copying and reproduction so long as the original work is given appropriate credit. Contents may not be used for commercial purposes, or adapted, remixed, transformed or built upon. (https://creativecommons.org/ licenses/by-nc-nd/4.0/)

Thieme Revinter Publicações Ltda., Rua do Matoso 170, Rio de Janeiro, RJ, CEP 20270-135, Brazil
} 
nerves. Afferent nerves from the UES end in the solitary nucleus, and the main motor nucleus of the sphincter is the nucleus ambiguous. ${ }^{2}$ The action of each muscle is directly related to the UES function, which may require either an increased or a reduced pressure in the sphincter.

In gastroesophageal reflux, the UES acts as a barrier to prevent the passage of esophageal refluxate into the pharynx, a situation that increases the risk of aspiration of gastric contents into the airways, causing acute and chronic pulmonary diseases. The UES also avoids the inhaling of air into the esophagus during inspiration. In patients with gastroesophageal reflux disease (GERD), although compensatory changes in the UES functioning may even improve the efficacy of the sphincter in preventing the occurrence of esophago-pharyngeal reflux, these changes may affect its efficiency during swallowing.

Gastroesophageal reflux disease has a prevalence of between 8 and 33\% in the world and affects individuals of both genders and all ages. ${ }^{9}$ The most common symptoms are heartburn and regurgitation ${ }^{10}$ caused by the reflux of gastric content, usually acid, to the esophagus. Also, supraesophageal symptoms may occur. Supraesophageal reflux can cause cough, laryngitis, asthma, dental erosion and voice alteration, and may be associated with pharyngitis, idiopathic pulmonary fibrosis and recurrent otitis. ${ }^{11}$

Normal UES opening during swallowing involves sphincter relaxation, anterior laryngeal traction, and intrabolus pressure ${ }^{12}$ and, therefore, functional or anatomical changes of the UES may cause impairment of UES opening and oropharyngeal dysphagia. We reviewed studies that evaluated the UES function in patients with GERD. The small number of studies about the UES in GERD and other diseases a long time ago is a consequence of methodological limitations until about the end of the decade of 1980 . When videofluoroscopy and highresolution manometry was introduced as a possibility for investigation, new knowledge about the pharyngeal-esophageal transition was developed. Investigations performed without the best methodology do not contribute significantly to the knowledge of UES physiology.

\section{Review of a Particular Subject}

A study using modern methodology describes an increase in the UES pressure when gastric contents reach thoracic and cervical segments of the esophagus during gastroesophageal reflux. ${ }^{13}$ The pressure response is similar in acid and nonacid liquid reflux, with an increase of $34 \pm 2 \mathrm{~mm} \mathrm{Hg}$ in patients with GERD and of $27 \pm 6 \mathrm{~mm} \mathrm{Hg}$ in patients without GERD. ${ }^{13}$ In healthy individuals, intraesophageal infusion of acid or nonacid fluids increase the UES pressure, ${ }^{6,7}$ and the pressure also increases with intraesophageal balloon distension. ${ }^{5}$ Swallowing a bolus with high levels of acidity does influence UES function, with a prolonged pressure restitution time after swallowing. ${ }^{14}$

In patients with obstructive sleep apnea, the esophageal pressure decreases (median reduction of $4.2 \mathrm{~mm} \mathrm{Hg}$ ) during episodes of apnea, which may favor the occurrence of gastroesophageal reflux. However, increases in the UES and in the lower esophageal sphincter (LES) pressure (medi- an of $20.1 \mathrm{~mm} \mathrm{Hg}$ in UES and of $9.6 \mathrm{~mm} \mathrm{Hg}$ in LES) promote the antireflux barrier against gastroesophageal and esophagopharyngeal refluxes during apnea. ${ }^{15}$ This is observed in obstructive sleep apnea patients with or without a diagnosis of GERD, although changes in the UES pressure are less intense in those without reflux disease.

In individuals with chronic GERD, the UES differs functionally from individuals without reflux disease, even at rest (that is, not during reflux episodes). A study evaluating UES motility in patients with GERD reported that almost half of the patients had a short and hypotonic UES, and in those with extraesophageal symptoms, the proportion of hypotonic UES was even higher. ${ }^{16}$ In another study, abnormalities in UES function were found in one-third of the patients with gastroesophageal reflux, including patients with laryngopharyngeal reflux and patients with typical GERD. The most common alteration was abnormal UES basal pressure (median of $59.8 \mathrm{~mm} \mathrm{Hg}$ ) in patients with GERD (normal reference value $73.5 \mathrm{~mm} \mathrm{Hg}$ ). ${ }^{17}$ In patients with esophagopharyngeal reflux, median UES resting pressure $(71 \mathrm{~mm} \mathrm{Hg}$ versus $126 \mathrm{~mm} \mathrm{Hg}$ in controls) and median proximal contractile integral ( $215.5 \mathrm{~cm} \mathrm{mmHg}$ versus $313.5 \mathrm{~cm} \mathrm{mmHg}$ in controls) were lower than in patients without pharyngeal reflux. ${ }^{18}$ On the other hand, there is an investigation with results that the UES may be hypertensive, a self-protective reaction in the esophagus in patients with esophageal chronic acid exposure, a situation that may cause cervical dysphagia, if the sphincter opening diameter decreases. ${ }^{19}$

The UES opening diameter during swallows of $20 \mathrm{~mL}$ liquid bolus, evaluated by videofluoroscopy in individuals with hiatal hernia, was lower $(0.81 \pm 0.24 \mathrm{~cm})$ than in individuals without hiatal hernia $(0.93 \pm 0.25 \mathrm{~cm}, p=0.02) .{ }^{20}$ Cricopharyngeal muscle dysfunction was seen in $78 \%$ of patients with hiatal hernia and in $58 \%$ of individuals without hiatal hernia in a sample of patients submitted to videofluoroscopy. ${ }^{20}$

Another UES dysfunction in patients with GERD is a slower passage of the swallowed bolus through the UES when compared with healthy controls (duration of flow: $0.61 \pm 0.02 \mathrm{~s}$ versus $0.53 \pm 0.02$ second in controls, $p=0.03) .{ }^{21}$ Similar findings were reported in another study evaluating swallowing of $5 \mathrm{~mL}$ of liquid bolus (duration of flow: $0.47 \pm 0.21$ second in patients with GERD and $0.39 \pm 0.10$ second in healthy controls, $p=0.01){ }^{22}$ A prolonged pharyngeal transit was also observed in patients with GERD $(0.83 \pm 0.04$ second compared with individuals without GERD ( $0.66 \pm 0.04$ second, $p=0.02)$, with an increased amount of pharyngeal residues in patients with GERD $(p=0.03) .{ }^{21}$ After swallowing of a $10 \mathrm{~mL}$ paste bolus, the pharyngeal transit time was $0.56 \pm 0.31$ second in patients and $0.47 \pm 0.21$ second in controls $(p=0.02) .{ }^{22}$ Patients with similar symptoms of GERD but with esophageal endoscopy without lesion and normal quantitative evaluation of the reflux, a situation named functional heartburn, do not have alteration of pharyngeal and UES transit, ${ }^{23}$ a demonstration that a longer UES and pharyngeal transit is consequence of gastroesophageal reflux and not of the symptoms.

An incomplete opening of the UES combined with a prolonged UES and pharyngeal transit time may be one of 
the causes of dysphagia in GERD patients. ${ }^{24-26}$ Reflux disease has been described as the most common disease associated with nonobstructive dysphagia ${ }^{24}$ and is reported by $47 \%$ of patients with esophagitis. ${ }^{25}$ Also, the prevalence of dysphagia was $48 \%$ among patients with heartburn and regurgitation, evaluated by patient self-perception. ${ }^{26}$ However, there are other possible explanations for dysphagia in patients with GERD, as hypersensitivity and esophageal motility abnormalities. ${ }^{26}$ Cricopharyngeal dysfunction is not an important cause of dysphagia in a significant proportion of patients with diseases that cause dysphagia. ${ }^{27}$ There are diverse effects of cultural variables on dysphagia, ${ }^{28}$ which cause different manifestations in similar situations.

In addition, in patients with GERD, there was a higher frequency (75.8\%) of UES pressure increase $(\geq 10 \mathrm{mmHg}$ from the baseline) during transient lower esophageal sphincter relaxation compared with healthy controls (17.6\%). Decrease in UES pressure during transient lower esophageal sphincter relaxation was observed in $21.2 \%$ of GERD patients and in $73.5 \%$ of controls. ${ }^{29}$

Electromyographic analysis of the cricopharyngeal muscle in GERD patients did not show differences as compared with findings in healthy volunteers. ${ }^{30}$ Also, a study assessing esophageal striated muscle contractions by manometry did not show different results between GERD patients with and without esophagitis. ${ }^{31}$

In healthy individuals, the slow infusion of liquid into the esophageal body causes an increase in the UES pressure, 6,7 which is not observed in patients with GERD with supraesophageal symptoms, indicating impairment in the UES response. $^{32}$ When gastroesophageal reflux is associated with cough, the UES residual pressure during swallowing is higher when compared with controls. ${ }^{33}$ The upper esophageal sphincter response to simulated slow and ultraslow reflux events is reduced in elderly individuals, suggesting that the aging process causes impairment of the UES response to gastroesophageal reflux. ${ }^{34}$

In cats, chronic esophageal acid exposure desensitizes the esophageal-UES relaxation and esophageal-UES contractile reflexes. ${ }^{35}$ In humans, there is a delay in airway closure relative to the arrival of the bolus at the UES in patients with GERD and dysphagia. ${ }^{36}$ There is a reflex interaction between pharynx, esophagus, and airways, ${ }^{37}$ which could be impaired in patients with GERD.

Gastroesophageal reflux symptoms, including significant heartburn, may be associated with a new syndrome called retrograde cricopharyngeal dysfunction (R-CPD), which causes inability to belch, abdominal pain, abdominal distention and excessive flatulence. ${ }^{38,39}$ The symptoms do not improve with conventional treatment for gastroesophageal reflux with proton pump inhibitors. The best-known treatment so far is botulinum toxin injection into the cricopharyngeal muscle. Whether the R-CPD syndrome is resultant of desensitization of the esophageal-UES relaxation caused by chronic esophageal acid exposure ${ }^{39}$ is a matter for future investigations. Gas presence in the esophageal body should decrease the UES pressure and cause a belch. ${ }^{40}$
Table 1 Summary of results of investigations about upper esophageal sphincter in gastroesophageal reflux

\begin{tabular}{|c|c|}
\hline Reference & UES alteration \\
\hline Torrico et al. ${ }^{13}$ & Increase pressure during reflux \\
\hline Kuribayashi et al. ${ }^{15}$ & Increase pressure during reflux \\
\hline Bognár et al. ${ }^{19}$ & Hypertensive sphincter \\
\hline Kim et al. ${ }^{29}$ & $\begin{array}{l}\text { Increase UES pressure during tran- } \\
\text { sient LES relaxation }\end{array}$ \\
\hline Babaei et al. ${ }^{32}$ & $\begin{array}{l}\text { No increase in pressure during slow } \\
\text { infusion of liquid into esophageal } \\
\text { body }\end{array}$ \\
\hline Nadaleto et al. ${ }^{16}$ & Short and hypotonic sphincter \\
\hline Benjamin et al. ${ }^{17}$ & Decreased pressure \\
\hline Passaretti et al. ${ }^{18}$ & $\begin{array}{l}\text { Decreased pressure in patients with } \\
\text { pharyngeal reflux }\end{array}$ \\
\hline Mendell et al. ${ }^{21}$ & $\begin{array}{l}\text { Slower transit through the } \\
\text { sphincter }\end{array}$ \\
\hline Cassiani et al. ${ }^{22}$ & $\begin{array}{l}\text { Slower transit through the } \\
\text { sphincter }\end{array}$ \\
\hline Alkan et al. ${ }^{30}$ & $\begin{array}{l}\text { No alteration of cricopharyngeal } \\
\text { EMG }\end{array}$ \\
\hline Bastian et al. ${ }^{39}$ & Inability to belch \\
\hline
\end{tabular}

Abbreviations: EMG, electromyography; LES, lower esophageal sphincter; UES, upper esophageal sphincter.

A summary of results about UES evaluation in GERD is in -Table 1.

\section{Discussion}

Gastroesophageal reflux disease symptoms have an incidence range that is different among countries. It is high in North America, Australia, Oceania, and Northern Europe; medium in Western Asia, Southern Asia, and South America; low in Eastern Asia, and Southern Europe. ${ }^{41}$ The most frequent symptoms of the disease are heartburn and regurgitation, with dysphagia considered an alarm symptom. Common causes of dysphagia in GERD are peptic stricture and severe inflammation; however, cancer and nonobstructive dysphagia are possibilities. ${ }^{26,42}$ When patients have progressive dysphagia and/or troublesome dysphagia, endoscopy is mandatory.

The UES is composed of striated muscle and responds to stimulus, increasing or decreasing its pressure. Dysphagia in GERD may be perceived in a situation of partial UES opening and slower bolus flow during swallowing; ${ }^{19,21,22}$ however, it is usually mild and may improve with clinical or surgical treatment of the disease. ${ }^{43}$ Swallows of a larger bolus volume cause an increase in UES opening duration and in UES diameter, ${ }^{12,44}$ with is restricted in patients with GERD. The increase in UES diameter caused by increase in bolus volume is associated with increase in the anterior maximal hyoid and laryngeal movements, ${ }^{12,44}$ which are adaptations to bolus 
volume that may be compromised in patients with GERD, with impairment of the UES opening diameter. ${ }^{20}$

It is proposed that GERD should be considered a family of syndromes with different pathophysiology, which include erosive GERD, nonerosive GERD, hypersensitive esophagus and functional heartburn, ${ }^{45}$ not always as a consequence of increased gastroesophageal reflux. The UES changes in patients with reflux symptoms is likely to be a consequence of the esophageal exposition to acidic reflux, and perhaps nonacidic reflux, but not of heartburn complaint.

The UES opening restriction can also increase the possibility of partial aspiration of the swallowed bolus into the airway, a situation that needs further investigation. The possibility of airway penetration in the disease is increased. $^{21}$

\section{Final Comments}

The UES of patients with GERD may not open as expected, which is associated with slower pharyngeal and UES transit. This behavior should aim to avoid the occurrence of esophagealpharyngeal reflux.

\section{Conflicts of Interest}

The author has no conflicts of interest to declare. Roberto O. Dantas is a member of the Board of Directors of the International Dysphagia Diet Standardization Initiative (IDDSI).

\section{References}

1 Lang IM, Shaker R. Anatomy and physiology of the upper esophageal sphincter. Am J Med 1997;103(5A):50S-55S

2 Lang IM. Upper esophageal sphincter. GI Motility Online, Part 1: Oral cavity, pharynx and esophagus, 2006

3 Perera L, Kern M, Hofmann C, et al. Manometric evidence for a phonation-induced UES contractile reflex. Am J Physiol Gastrointest Liver Physiol 2008;294(04):G885-G891

4 Kahrilas PJ, Dodds WJ, Dent J, Haeberle B, Hogan WJ, Arndorfer RC. Effect of sleep, spontaneous gastroesophageal reflux, and a meal on upper esophageal sphincter pressure in normal human volunteers. Gastroenterology 1987;92(02):466-471

5 Andreollo NA, Thompson DG, Kendall GPN, Earlam RJ. Functional relationships between cricopharyngeal sphincter and oesophageal body in response to graded intraluminal distension. Gut 1988;29(02):161-166

6 Andreollo NA, Thompson DG, Kendall GP, McIntyre AS, Earlam RJ. Motor responses of the upper esophageal sphincter and body to intraluminal acid. Braz J Med Biol Res 1989;22(01):51-60

7 Gerhardt DC, Shuck TJ, Bordeaux RA, Winship DH. Human upper esophageal sphincter. Response to volume, osmotic, and acid stimuli. Gastroenterology 1978;75(02):268-274

8 Bitnar P, Stovicek J, Andel R, et al. Leg raise increases pressure in lower and upper esophageal sphincter among patients with gastroesophageal reflux disease. J Bodyw Mov Ther 2016;20 (03):518-524

9 Gyawali CP, Kahrilas PJ, Savarino E, et al. Modern diagnosis of GERD: the Lyon Consensus. Gut 2018;67(07):1351-1362

10 Vaezi MF, Sifrim D. Assessing old and new diagnostic test for gastroesophageal reflux disease. Gastroenterology 2018;154 (02):289-301
11 Richter JE. The many manifestations of gastroesophageal reflux disease: presentation, evaluation, and treatment. Gastroenterol Clin North Am 2007;36(03):577-599, viii-ix

12 Cook IJ, Dodds WJ, Dantas RO, et al. Opening mechanisms of the human upper esophageal sphincter. Am J Physiol 1989;257(5 Pt 1):G748-G759

13 Torrico S, Kern M, Aslam M, et al. Upper esophageal sphincter function during gastroesophageal reflux events revisited. Am J Physiol Gastrointest Liver Physiol 2000;279(02):G262-G267

14 Miller S, Ptok M, Jungheim M. Influence of acid swallows on the dynamics of the upper esophageal sphincter. Dysphagia 2020

15 Kuribayashi S, Massey BT, Hafeezullah M, et al. Upper esophageal sphincter and gastroesophageal junction pressure changes act to prevent gastroesophageal and esophagopharyngeal reflux during apneic episodes in patients with obstructive sleep apnea. Chest 2010;137(04):769-776

16 Nadaleto BF, Herbella FAM, Pinna BR, Patti MG. Upper esophageal sphincter motility in gastroesophageal reflux disease in the light of the high-resolution manometry. Dis Esophagus 2017;30(04): 1-5

17 Benjamin T, Zackria S, Lopez R, Richter J, Thota PN. Upper esophageal sphincter abnormalities and high-resolution esophageal manometry findings in patients with laryngopharyngeal reflux. Scand J Gastroenterol 2017;52(08):816-821

18 Passaretti S, Mazzoleni G, Vailati C, Testoni PA. Oropharyngeal acid reflux and motility abnormalities of the proximal esophagus. World J Gastroenterol 2016;22(40):8991-8998

19 Bognár L, Vereczkei A, Papp A, Jancsó G, Horváth ÖP Gastroesophageal reflux disease might induce certain - supposedly adaptative - changes in the esophagus: a hipothesis. Dig Dis Sci 2018;63(10): 2529-2535

20 Nativ-Zeltzer N, Rameau A, Kuhn MA, Kaufman M, Belafsky PC. The relationship between hiatal hernia and cricopharyngeus dysfunction. Dysphagia 2019;34(03):391-396

21 Mendell DA, Logemann JA. A retrospective analysis of the pharyngeal swallow in patients with a clinical diagnosis of GERD compared with normal controls: a pilot study. Dysphagia 2002;17 (03):220-226

22 Cassiani RA, Mota GA, Dantas RO. Oral and pharyngeal bolus transit in gastroesophageal reflux disease. Esophagus 2015;12 (04):345-351

23 Cassiani RA, Dantas RO. Oral and pharyngeal transit in functional heartburn. Arq Gastroenterol 2020;57(02):150-153

24 Kidambi T, Toto E, Ho N, Taft T, Hirano I. Temporal trends in the relative prevalence of dysphagia etiologies from 1999-2009. World J Gastroenterol 2012;18(32):4335-4341

25 Triadafilopoulos G. Nonobstructive dysphagia in reflux esophagitis. Am J Gastroenterol 1989;84(06):614-618

26 Batista AO, Nascimento WV, Cassiani RA, et al. Prevalence of nonobstructive dysphagia in patients with heartburn and regurgitation. Clinics (São Paulo) 2020;75:e1556

27 Baredes S, Shah CS, Kaufman R. The frequency of cricopharyngeal dysfunction on videofluoroscopic swallowing studies in patients with dysphagia. Am J Otolaryngol 1997;18(03):185-189

28 Koidou I, Kollias N, Sdravou K, Groios G. Dysphagia: a short review of the current state. Educ Gerontol 2013;39(11):812-817

$29 \mathrm{Kim} \mathrm{HI}$, Hong SJ, Han JP, et al. Specific movement of esophagus during transient lower esophageal sphincter relaxation in gastroesophageal reflux disease. J Neurogastroenterol Motil 2013;19 (03):332-337

30 Alkan Z, Demir A, Yigit O, et al. Cricopharyngeal muscle electromyography findings in patients with gastroesophageal reflux disease. Otolaryngol Head Neck Surg 2012;147(02):295-301

31 Dantas RO, Aprile LRO. Esophageal striated muscle contractions in patients with gastroesophageal reflux symptoms. Dig Dis Sci 2002;47(11):2586-2590 
32 Babaei A, Venu M, Naini SR, et al. Impaired upper esophageal sphincter reflexes in patients with supraesophageal reflux disease. Gastroenterology 2015;149(06):1381-1391

33 Vardar R, Sweis R, Anggiansah A, Wong T, Fox MR. Upper esophageal sphincter and esophageal motility in patients with chronic cough and reflux: assessment by high-resolution manometry. Dis Esophagus 2013;26(03):219-225

34 Mei L, Dua A, Kern M, et al. Older age reduces upper esophageal sphincter and esophageal body responses to simulated slow and ultraslow reflux events and post-reflux residue. Gastroenterology 2018;155(03):760-770.e1

35 Lang IM, Medda BK, Shaker R. Effects of esophageal acidification on esophageal reflexes controlling the upper esophageal sphincter. Am J Physiol Gastrointest Liver Physiol 2019;316(01): G45-G54

36 Kendall KA. Airway closure delay: the predominant pathophysiology in reflux-associated dysphagia. Otolaryngol Head Neck Surg 2019;160(05):885-890

37 Shaker R. Reflex interation of pharynx, esophagus, and airways. . GI Motility Online, Part 1: Oral cavity, pharynx and esophagus, 2006

38 Sato H, Ikarashi S, Terai S. A rare case involving the inability to belch. Intern Med 2019;58(07):929-931
39 Bastian RW, Smithson ML. Inability to belch and associated symptoms due to retrograde cricopharyngeal dysfunction: diagnosis and treatment. OTO Open 2019;3(01):X19834553

40 Kahrilas PJ, Dodds WJ, Dent J, Wyman JB, Hogan WJ, Arndorfer RC. Upper esophageal sphincter function during belching. Gastroenterology 1986;91(01):133-140

41 Hunt R, Armstrong D, Katelaris P, et al;Review Team. World Gastroenterology Organisation global guidelines. GERD global perspective on gastroesophageal reflux disease. J Clin Gastroenterol 2017;51(06):467-478

42 Richter JE, Rubenstein JH. Presentation and epidemiology of gastroesophageal reflux disease. Gastroenterology 2018;154 (02):267-276

43 Vakil NB, Traxler B, Levine D. Dysphagia in patients with erosive esophagitis: prevalence, severity, and response to proton pump inhibitor treatment. Clin Gastroenterol Hepatol 2004;2(08): 665-668

44 Dantas RO, Kern MK, Massey BT, et al. Effect of swallowed bolus variables on oral and pharyngeal phases of swallowing. Am J Physiol 1990;258(5 Pt 1):G675-G681

45 Katzka DA, Pandolfino JE, Kahrilas PJ. Phenotipes of gastroesopageal reflux disease. Where Rome, Lyon, and Montreal meet. Clin Gastroenterol Hepatol 2020;18(04):767-776 